\title{
RELATO DE EXPERIÊNCIA: O GÊNERO RESUMO ACADÊMICO EM FOCO
}

Sandro Luis da Silva*

\begin{abstract}
Resumo: Este artigo apresenta o relato de experiência no trabalho realizado com o gênero "resumo". Elegeu-se como categoria de análise a referência bibliográfica, a coesão e a coerência textuais e as expressões e verbos que remetessem à voz do autor do texto. O corpus são vinte resumos elaborados pelos alunos do primeiro semestre do curso de Gestão Empresarial em uma Faculdade Pública de São Paulo, escolhidos aleatoriamente entre os sessenta da turma. O estudo pauta-se em Machado (2005) e Matêncio (2003) quanto ao gênero, em Koch (2002) e em Kleiman (1992) quanto ao texto, à leitura e à produção de sentido. Os alunos apresentam dificuldades na produção do resumo, com defasagem no processo de leitura de um texto.
\end{abstract}

Palavras-chave: Resumo. Leitura. Escrita. Expressões Introdutórias.

\begin{abstract}
This article presents the results a research on the teaching of the genre summary. The bibliographic reference; the cohesion and the textual coherence along with the expressions and the verbs that reflect the voice of the author of the text summarized were selected as categories of analysis. The corpus is made of twenty summaries prepared by students of the first semester of a Business Management course in a Public College in São Paulo, randomly chosen in the class. The study is based on Machado (2005) and Matêncio (2003) regarding genre and in Koch (2002) and Kleiman (1992) regarding text, reading and meaning production. Students have difficulties in producing summaries and in the process of reading a text.
\end{abstract}

Keywords: Summary. Reading. Writing. Introductory Expressions.

\section{Considerações iniciais}

Os trabalhos acadêmicos têm, dentre vários objetivos, difundir a produção do conhecimento em uma determinada área do saber. São textos que expressam certo conhecimento do mundo e que se diferenciam de outras expressões simbólicas, uma vez que se constituem de textos sistematizados - frutos da pesquisa, elaboração e compreensão de um fenômeno - e organizados de acordo com algumas orientações, que sustentam as produções das comunidades acadêmicas.

Ao chegar à Universidade, os alunos se deparam com uma série de atividades de leitura e de produção textual bastante intensa e, na maioria das vezes, diferentes daquelas desenvolvidas na escola básica. Eles passam a produzir gêneros que atendem ao domínio discursivo acadêmico, como, por exemplo, resenhas, resumos, artigos, dentre outros presentes no dia a dia de sua formação inicial. Dentro da realidade em que se encontra a Educação brasileira hoje, infelizmente, os acadêmicos chegam à universidade com dificuldades na leitura e na produção dos mais variados textos.

Os diferentes gêneros acadêmicos são elaborados de acordo com as normas preestabelecidas e com os fins a que se destinam, refletindo dúvidas, (in)certezas e processos resultantes do enfrentamento com o mundo. A maior preocupação dos alunos é em relação aos textos escritos. A escrita constitui-se em uma prática social de natureza situada, que visa à interação entre os sujeitos, expressando valores, crenças, ideologias, pontos de vista, enfim, ao escrever, o produtor do texto coloca sua voz no texto, levando o leitor a construir um ethos discursivo tendo em vista o momento da enunciação.

\footnotetext{
* Doutor em Língua Portuguesa pela PUC/SP. Professor Adjunto de Língua Portuguesa no Departamento de Letras da Universidade Federal de São Paulo (UNIFESP). Endereço eletrônico: vitha75@ gmail.com
} 
Vale lembrar que o ethos discursivo é entendido como um modo de ser de um sujeito e de se apresentar no mundo, de cuja imagem se depreendem um tom de voz, uma corporalidade e um caráter. Lembremos, assim, as palavras de Maingueneau (1997, p.46): "Mas o tom, por si só, não recobre, em seu conjunto, o campo do ethos enunciativo. O tom está necessariamente associado a um caráter e a uma corporalidade". Maingueneau (1997, p.99) ainda complementa: "o ethos implica, com efeito, uma disciplina do corpo apreendido por intermédio de um comportamento global".

Produzir conhecimento pressupõe, assim, textos escritos - e é nessa escrita que o conhecimento se manifesta, revelando a compreensão da realidade, considerando-se os elementos constitutivos do universo de relações culturais, sociais e interpessoais vivenciadas. Nesse novo contexto em que se encontra o aluno - vida acadêmica - há uma mudança de perspectiva em relação à escrita: deixa de ter uma visão extremamente estruturalista, inflexível para uma forma mais dinâmica, que precisa atender às necessidades de comunicação numa dada situação enunciativa.

Tendo em vista essa nova realidade que se configura no contexto escolar, o objetivo deste artigo é apresentar o relato de uma atividade realizada, durante o segundo semestre de 2011, junto aos alunos do primeiro semestre do curso de Tecnologia em Gestão Empresarial em uma Faculdade do interior de São Paulo e refletir sobre o processo de ensinoaprendizagem de língua portuguesa por meio da produção textual, em especial, com os gêneros acadêmicos.

Durante as aulas de Comunicação e Expressão, trabalhou-se o gênero acadêmico resumo, abordando sua finalidade e os mecanismos linguísticos que o caracterizam, assim como a necessidade de evidenciar que esse gênero constitui-se, também, em um processo de leitura que requer análise e interpretação. Nosso olhar recai mais especificamente sobre a utilização de verbos e expressões introdutórias do discurso do Outro na elaboração de resumo de textos e, ainda, sobre a presença da voz do autor do resumo, a fim de verificar em que medida essa voz revela a leitura textual realizada pelo aluno.

De acordo com Machado (2005), tem se tornado significativo o uso social dos resumos, o que justifica uma reflexão sobre esse gênero textual, levando em consideração o contexto de produção no espaço da Universidade, como uma forma de exercitar a leitura e a escrita de texto acadêmico.

A linguagem do mundo atual privilegia modalidades diferentes da escrita, valendose, inclusive, dos grandes recursos das novas tecnologias, que vêm somando novidades ao processo comunicacional. Esses eventos devem ser vistos numa nova perspectiva que acaba por caracterizar mais um dos modos de representação cultural e que contribuem decisivamente no processo comunicacional.

É pressuposto, neste texto, que a linguagem é uma construção social, em que dialogia e interação se constituem como seus elementos fundamentais. Considera-se, ainda, que a compreensão do domínio da própria autonomia discursiva também é construída na interação social que se realiza entre os interlocutores numa situação enunciativa.

Vale lembrar que o resumo é um tipo específico de retextualização que obedece a determinadas condições de leitura e de produção textual, além da circulação e recepção do texto fonte. A produção de um resumo constitui-se em uma estratégia didática, que leva os alunos ao exercício de uma escrita coesa e coerente, a partir da leitura de um texto-base proposto. Para que a atividade seja bem sucedida, é preciso considerar o papel dos interlocutores, as funções e os objetivos da comunicação que se pretende estabelecer por meio deste gênero textual.

A retextualização corresponde a uma atividade linguística, cujo objetivo é transformar um gênero em outro. Essas alterações foram observadas e estudadas por 
Marcuschi (2001), para quem as transformações ocorrem automaticamente pelos usuários de uma língua, sem que seja dada conta da complexidade dessas operações.

Para Dell'Isola (2007, p. 41), “A prática da escrita de gêneros textuais orientadas pela leitura de um texto e pelo desafio de transformar seu conteúdo em outro gênero, mantendo a fidelidade às suas informações de base, é uma atividade bastante produtiva". E a prática de elaborar resumos atende ao proposto por Dell'Isola, pois os alunos não só reproduzem a ideia do autor do texto base, como produzem textos; torna-se uma prática que envolve o desenvolvimento da habilidade de leitura e de produção textual.

De acordo com Matêncio (2003, p. 9), "a ação de resumir pressupõe selecionar macroproposições, relacioná-las em função dos propósitos atribuídos ao autor do texto-base ou dos propósitos de uma nova preposição". É preciso que seja conhecida a configuração e o funcionamento desse gênero textual.

Para Marcuschi (2005), os gêneros textuais são realizações linguísticas concretas definidas por propriedades sócio-comunicativas; constituem textos empiricamente realizados, cumprindo funções em situações comunicativas. Para Dolz e Schneuwly (2004), os gêneros textuais caracterizam-se como um princípio mediador entre as práticas sociais e os objetos escolares, por meio dos quais se desenvolvem várias habilidades do aluno, dentre elas a de comunicar-se com seus pares, interagindo, argumentando, expondo pontos de vista, enfim, posicionando-se diante da realidade. Dessa forma, é facultado a ele o direito de construir sentidos para o texto, numa atitude ativa, crítica e reflexiva, relacionando-a com a realidade da qual ele faz parte.

Entende-se por resumo, nos limites deste trabalho, o gênero em que se expressa a ideia central de um texto-base, respeitando a ideia de seu autor e a lógica textual, ou seja, consiste na apresentação concisa dos pontos relevantes de um texto. Assim, elaborar um resumo tecnicamente correto significa expor o que há de essencial no texto, obedecendo a uma hierarquia do texto-base e à mesma sequência que nele aparece.

O texto é a concretização de um discurso o qual é constituído por algumas operações que existem historicamente no ambiente sócio-cultural, das quais o ser humano se apropria no processo de interação social. A produção de um texto envolve a manifestação de operações de ação discursiva e linguístico-discursiva.

Afirma Koch (2002, p.7): "o sentido de um texto é, portanto, construído na interação texto-sujeitos (ou texto-co-enunciadores) e não algo que preexista a essa interação”. Portanto, infere-se que, ao ler e resumir um texto, o aluno constrói um sentido para o texto lido por meio de sua retextualização.

\section{Procedimentos metodológicos}

O objeto de análise deste relato de experiência foram vinte textos (resumos) produzidos por alunos ${ }^{1}$ com faixa etária entre 19 e 29 anos, do primeiro semestre do curso de Tecnologia em Gestão Empresarial, numa universidade pública no Estado de São Paulo, os quais vêm, na sua maioria, de cursos regulares da escola básica pública. Para a realização da atividade, foram adotados os seguintes procedimentos metodológicos: após um momento de explicação teórica sobre o conceito de resumo e os mecanismos linguísticos pertencentes a esse gênero acadêmico, foi proposta aos alunos a atividade de resumir um texto. Há de se levar em consideração que o conceito de texto, o de discurso, o de construção de sentido e

\footnotetext{
${ }^{1}$ Os sujeitos desta pesquisa serão designados por aluno 1 , aluno 2 , sucessivamente.
} 
suas implicações já haviam sido trabalhados anteriormente. Não se pode desconsiderar que se tratava da primeira experiência acadêmica de produção textual dos alunos.

Realizada a parte teórico-explicativa, propusemos a leitura do texto de Luckesi (2003) - "O conhecimento como compreensão do mundo e como fundamentação da ação", para que fosse realizado, então, o exercício de retextualização, a partir do resumo. A atividade de leitura e produção textual ocorreu extraclasse e individualmente.

A escolha desse texto ocorreu em virtude da proposta que o autor faz em refletir sobre o 'conhecimento' como uma forma de libertação, de ação e de transformação de si e do mundo. $\mathrm{O}$ autor trabalha $\mathrm{o}$ assunto de maneira didática, com uma linguagem bastante acessível aos alunos do primeiro semestre de um curso de graduação.

Os discentes tiveram quinze dias para realizar a tarefa proposta. Saliente-se que, nesse intervalo, o professor sempre fazia intervenções sobre a atividade de escrita, chamando a atenção dos alunos para o texto que eles produziam extraclasse. Ao receber a produção escrita, verificou-se em que medida a produção textual atendia aos aspectos ligados à estrutura, à coerência e à coesão do resumo acadêmico. Em seguida, levantaram-se os verbos e expressões introdutores da voz do autor e, consequentemente, como essa era registrada nos resumos apresentados.

Numa abordagem qualitativa, foram eleitos como categoria de análise os seguintes itens: a referência bibliográfica, a coesão e a coerência textuais e as expressões e verbos que remetessem à voz do autor do texto, a fim de atender aos propósitos desta pesquisa.

\section{A produção textual: o resumo e as operações linguísticas}

A sala de aula constitui-se em um espaço das diferenças, do embate de vozes, estruturada com as diferentes percepções de mundo (REGIS, 2005). Trata-se de um lugar em que o olhar dos sujeitos deve estar voltado para a agência. De acordo com Miller (2012), "agência" significa a capacidade dos sujeitos de ajustar a sua responsividade a situações problemáticas, voltadas para a prática social. Ela precisa estar organizada de tal forma que os sujeitos evidenciem suas intenções, realizem interações significativas, estabelecendo relações sociais e culturais, locais e globais.

É preciso ter clareza de que, conforme Geraldi (2010, p. 103),

Ler não é apenas reconhecer o signo com suas significações do passado. Ler é construir uma compreensão no presente com significações que, entranhadas nas palavras, são dissolvidas pelo seu novo contexto - que incluem também as contrapalavras do leitor - para permitir a emergência de um sentido concreto, específico e único, produto da leitura que se está realizando.

E Geraldi continua

A leitura é também co-produção do texto, uma atividade orientada por este, mas que lhe ultrapassa. O reconhecimento do que já é conhecido é uma condição necessária para que se dê a leitura, mas não é condição suficiente. É preciso ultrapassar o já sabido e reconhecido para construir uma compreensão do que se lê (do que se ouve). (GERALDI, 2010, p. 103).

A elaboração de um texto exige do sujeito - produtor (enunciador) - uma reflexão do contexto em que está inserido e o do enunciado, para que possa obter a resposta esperada e 
promover a interação com seu interlocutor, objetivo primeiro da comunicação. O domínio da tecnologia da escrita, na atualidade, está relacionado ao domínio de várias estratégias de escrita e, consequentemente, de interação social.

É pressuposto, neste texto, que a linguagem é uma construção social, em que dialogia e interação se constituem como seus elementos fundamentais. Considera-se, ainda, que a compreensão do domínio da própria autonomia discursiva também é construída na interação social que se realiza entre os interlocutores numa situação enunciativa.

Há de se considerar que todo e qualquer texto é dialógico, na concepção dada por Bakhtin (1992), uma vez que, ao produzir um texto, aciona-se todo o conhecimento dos sujeitos a respeito do tema, da estrutura, da função social do texto, que se enquadra em um gênero.

O texto, segundo a concepção interacionista, é considerado como a materialização de uma ação de linguagem constituída por determinadas operações que já existem historicamente e o leitor apropria-se delas.

Para Costa Val (1999), "um texto é uma unidade de linguagem em uso, cumprindo uma função identificável num dado jogo de atuação sociocomunicativa" (p.3-4). Segundo a autora, uma série de fatores pragmáticos contribui para a produção e a recepção do texto, como, por exemplo, intenção do produtor, jogo de imagens mentais que cada um dos interlocutores faz de si, do outro e do outro com relação a si mesmo e ao tema. Ela afirma que o texto se caracteriza por sua unidade formal. Assim, um texto será bem compreendido quando avaliado sob os aspectos: 1) pragmáticos; 2) semântico-conceitual; 3) formal. É interessante observar que a autora não faz distinção explícita entre texto e discurso.

Van Dijk (2008, p. 18), por sua vez, afirma ser o texto o resultado de um processo que se perfaz "numa totalidade integrada por uma unidade temática, um formato e cuja significação se alcança mediante a relação entre seus constituintes e seu contexto de produção".

O autor entende, portanto, o texto não como produto, mas como processo, forma de enunciação textual, concebendo, assim, a textualidade como modo de processamento e não como conjunto de propriedades inerentes ao texto reduzido a sua dimensão de produto.

Tendo em vista essas considerações iniciais sobre texto, não há como pensar na produção textual sem levar em consideração a leitura, que não admite um sujeito paralisado, acrítico, não reflexivo. A leitura de um texto requer um leitor que consiga identificar e caracterizar os elementos essenciais e os secundários que permeiam o conteúdo do texto, sem desprezar, evidentemente, os aspectos estruturais.

É importante lembrar que, vista como um ato de comunicação, a leitura envolve uma relação cooperativa entre os participantes, transmissão de intenções e conteúdos, adequação de uma forma à sua função e a um contexto sócio-histórico, como aponta Kleiman (1992). Durante o processo de leitura, o leitor tem de se esforçar para recuperar, seja por meio de seu conhecimento prévio, seja por meio de marcas no texto, o contexto situacional e o contexto sócio-histórico, para perceber a intenção comunicativa presente no texto, promovendo a interação.

Para produzir um texto, o autor envolve três tipos de operação, a saber: capacidade de ação, capacidade discursiva e capacidade linguístico-discursiva. O trabalho escolar com expressão escrita também precisa contemplar os diferentes tipos de leitura e de escrita, guiando-nos pelas operações realizadas pelo sujeito e pelas capacidades de linguagem que devem mobilizar. Por capacidades, Dolz e Schneuwly (2004) consideram:

a) capacidades de ação: o reconhecimento do gênero e de sua relação com o contexto de produção e mobilização de conteúdos; 
b) capacidades discursivas: o reconhecimento do plano textual geral de cada gênero, os tipos de discurso e de sequência mobilizados;

c) capacidades linguístico-discursivas: o reconhecimento e a utilização do valor das unidades linguístico-discursivas próprias a cada gênero para a construção do significado global do texto.

Neste trabalho, nos limitamos ao terceiro tipo, uma vez que implicam operações relacionadas ao domínio daquelas diretamente ligadas à produção textual, isto é, ao uso efetivo das unidades linguísticas, embora essa classificação seja apenas do ponto de vista didático, pois para a elaboração textual, elas estão em interação permanente. É importante que o produtor textual tenha competência para utilizar essas três operações a fim de produzir com o efeito de sentido desejado.

As operações linguístico-discursivas envolvem textualização (que explicitam as relações entre os diferentes segmentos textuais), estabelecimento de responsabilidades enunciativas (gerenciamento de vozes) e construção de enunciados e de seleção lexical.

É importante lembrar que o gênero resumo é resultante de uma ação comunicativa, como uma transmissão de um discurso existente em função de um novo receptor e outro objetivo. Levando-se em consideração esses aspectos é que este trabalho se norteará para analisar os resumos objetos de estudo.

\section{0 resumo na prática universitária}

Como já apontamos anteriormente, o resumo constitui-se em uma prática de retextualização com traços linguísticos específicos no texto. Segundo a Norma NBR 6028, da ABNT, o resumo tem de ser "a apresentação concisa dos pontos relevantes de um texto". Nesse sentido, espera-se um texto-resumo com uma característica básica: concisão.

Schneuwly e Dolz (1999) revelam que a cultura do sistema escolar define o resumo como uma representação reduzida do texto que será resumido, sendo o problema de escrita reduzido a um simples ato de transcodificação da compreensão do texto.

A referência bibliográfica foi o primeiro elemento analisado no texto dos alunos. Para a maioria deles, apenas sinalizar o título do texto-base já é suficiente, embora, durante as discussões sobre a estrutura do resumo, eles tenham sido alertados sobre a importância da referência bibliográfica no texto acadêmico. Inferimos que tal fato tenha ocorrido pela situação de produção textual, ou seja, eles acreditavam que, por estar compartilhando a leitura com o professor de Comunicação e Expressão, a referência não assumiria importância.

Alguns exemplos da identificação marcada pelos alunos:

$>\quad$ "O conhecimento como Compreensão do Mundo e Fundamentação de ação" (aluno 1);

$>\quad$ "Resumo do texto do Luckesi" (aluno 3);

$>\quad$ "LUCKESI, C. et alli. Fazer Universidade: uma proposta metodológica. 14 ed. São Paulo: Cortez, 2005" (aluno 12).

Esses são alguns exemplos das referências anotadas pelos alunos ao se referirem ao texto-base. Embora tenha sido trabalhada em aula a referência bibliográfica, observa-se, ainda, que a falta de identificação do texto-base gera como consequência uma descaracterização do funcionamento discursivo do gênero em questão.

Outro ponto a ser considerado é a questão da estratégia de redução. Dentre os vinte textos objetos deste trabalho, a estratégia mais utilizada foi a cópia de trechos considerados 
relevantes do texto-base pelos alunos. Isso implicou problemas de coesão e de coerência textuais, como se observa no exemplo abaixo:

Podemos dizer que o homem quando não possui ciência sobre algo, este não age, pois não possui orientação. Um exemplo disso é quando o homem atribui a ocorrência de um evento ao sobrenatural (aluno 1).

No mesmo momento em que o aluno se refere à inércia do homem, ele afirma que o homem pratica uma atribuição "de um evento ao sobrenatural". O "colar e copiar" do textobase, sem se ater ao conteúdo trazido pelo autor, sem observar a sequência lógica exigida por todo e qualquer texto, leva à inadequação do gênero. A coerência apresenta-se como um princípio de interpretabilidade do texto, envolvendo fatores de ordem cognitiva, interacional e linguística. Este princípio se relaciona à estrutura do texto, estabelecendo a partir de uma unidade de sentido o que a caracteriza como ato global, ou seja, refere-se ao texto como um todo. aluno 3:

Um exemplo de problema de coesão e de coerência é apresentado no resumo do

Teoria e prática, ação e reflexão são vertentes estes necessários acessão do conhecimento. A saída da ignorância é um veículo de libertação da submissão.

A socialização do conhecimento é um direito de todos os seres humanos e não um privilegio.

Como se observa, a falta de correção gramatical e a incoerência implicam a dificuldade de produção de efeito de sentido por parte do leitor.

Outro exemplo que registra problemas quanto à redação é o escrito pelo aluno 7:

Segundo o autor lido, o autor nos apresenta três vertentes para o conhecimento. O conhecimento como mecanismo de compreensão e transformação do mundo. $\mathrm{O}$ conhecimento como uma necessidade para a ação. E por fim, o conhecimento como elemento de liberação.

Além da construção paralelística, a escrita do aluno traz repetições desnecessárias; ele faz referência ao "autor" de maneira inadequada para o gênero, colocando uma expressão de conformidade seguida pelo sujeito; não há necessidade da repetição, o que implica estranheza para o leitor ao deparar com o texto. Como apontamos anteriormente, uma das características do gênero resumo é a concisão.

Um texto é o resultado do diálogo com outros textos e, no caso do resumo, é o diálogo com um texto-base, a partir do qual ocorre uma retextualização. É preciso considerar em que medida o resumo explicita a voz do autor do texto-base, para compreender a leitura feita pelo aluno, ao resumir o texto. Vale lembrar que o pensamento do outro é constitutivo desse discurso; não é possível separá-los radicalmente - o que permite apontar, conforme Bakhtin (1992), a centralidade da linguagem na constituição de subjetividades.

O resumo é um gênero textual em que se evidencia a pluralidade de vozes de diferentes sujeitos: a voz do autor do texto-base e a voz do autor do resumo. Considera-se que vozes de outros sujeitos, delegadas por um 'eu', podem ser instaladas com o propósito de atribuir a esses sujeitos um poder-fazer. 
Analisando o texto dos sujeitos desta pesquisa, observamos que trouxeram, em alguns momentos do resumo, a voz do autor (LUCKESI, 2003), de forma marcada, como observamos no trecho abaixo, escrito pelo aluno 14 :

O autor nos diz que a ação é a base imprescindível para se obter conhecimento, transformando-o em direção da ação. Já o conhecimento, em si próprio, é o mecanismo base para se obter uma vida plena e satisfatória.

Outro exemplo, escrito pelo aluno 15:

Segundo Luckesi, para adquirirmos o conhecimento, como entendimento do mundo, temos que observar e analisar nossas atitudes e pensamentos, assim tornamos nossas atitudes e organizamos tudo ao nosso redor de uma forma mais prazerosa.

No primeiro exemplo, o aluno 14 explicita a voz do autor por meio da expressão "o autor nos diz que..." e, no texto do aluno 15, "segundo Luckesi". Em ambos os casos, temos a voz marcada do autor do texto-base, com o qual o resumo dialoga em seu conteúdo. Nesse caso, o texto evidencia o discurso dos alunos, mas sem se desprender da voz presente do texto-base. $\mathrm{O}$ aluno, como enunciador do gênero resumo, tem a expectativa reforçada: ele espera a delegação de vozes, como leitor normatizado pelo gênero.

Essas expressões reforçam o diálogo do resumo com o texto-base. Infere-se que o aluno manteve-se fiel às ideias do autor. Esses dois exemplos demonstram que o objetivo do gênero textual resumo, nesse momento, foi cumprido, ou seja, não há qualquer evidência de avaliação do texto por parte do resumista, tampouco um "copia e cola"; ateve-se às ideias principais do texto, segundo o autor.

O resumo, dentro do domínio discursivo acadêmico, é construído como reflexo de normas, valores e prática socialmente estabelecidas por um grupo, que se definem por suas práticas discursivas. E mais: ele também é construído como reflexo da interação projetada entre autor e leitor, como exemplifica o corpus deste trabalho.

Ao resumir, instala-se a intertextualidade, na concepção dialógica bakhtiniana, uma vez que para o autor russo "o diálogo é a única esfera possível da vida da linguagem" (FIORIN, 2012, p. 163). Esse diálogo torna o texto uma prática significante, isto é, "a significação se produz, não no nível de uma abstração (língua), tal como postulara Saussure, mas como uma operação, um trabalho, em que se investem, ao mesmo tempo e num só movimento, o debate do sujeito e do Outro e contexto social" (BARTHES, 1994, p. 1681, apud FIORIN, 2012, p. 164).

Seis dos vinte resumos analisados marcam a voz do autor do texto-base somente no início do resumo. Depois, basicamente os autores fazem cópia do texto, caracterizando, inclusive, mudança de voz textual: iniciam na terceira pessoa do singular e passam para a primeira do plural, tal qual encontramos no texto-base.

Alguns resumos apresentam, no seu desenvolvimento, expressões em que o aluno explicita uma operação linguística como operações de organização sequencial, caracterizadas pelo exemplo abaixo:

O autor começa afirmando que quando não conhecemos inteiramente uma situação, estamos submetidos a ela, mas na medida em que saímos do estado de ignorância dominando aquela situação, nos permitindo agir com segurança e certeza. (aluno 5) 
Há outras formas verbais, como esclarece, as quais indicam que o aluno interpreta que o texto resumido desenvolve a operação de organização do objeto discursivo em forma de sequência explicativa:

$\mathrm{Na}$ terceira parte do texto, o autor esclarece a idéia do conhecimento como elemento de libertação, a conjunção entre compreensão e necessidade do conhecimento (dois pontos anteriores discutidos pelo autor) (aluno 7).

Ao utilizar o verbo esclarecer, o aluno interpreta a organização sequencial, considerando que o conteúdo temático é visto pelo autor do texto-base como de difícil compreensão. Contata-se, neste exemplo, a presença da voz do resumista, que evidencia a relação autor/texto-base, apreendendo o sentido que a forma verbal imprime para o textobase.

Os alunos, ao resumirem o texto, apresentam diferentes verbos relacionados a segmentos expositivos, como os verbos definir, lançar, analisar e denominar, que não se referem a uma forma de organização convencional, mas a outras formas chamadas de esquematização. Exemplificando:

O texto analisa as questões do conhecimento, discutindo as questões teóricopráticas e prático-teóricas, a fim de produzir um sentido para entender a realidade do mundo, pois só você assim se sente realizado e melhore seu modo de viver do que decorar fórmulas que são desinteressantes a nossa existência (aluno 9).

Ao valer-se do verbo analisar o aluno interpreta que o autor desenvolveu operações de decompor um todo em seus elementos constitutivos. Infere-se que o aluno interpreta que o autor do texto-base organizou partes de seu texto em forma de análise.

Observamos em dois textos a utilização da forma verbal "enfatiza":

No segundo ponto, o conhecimento como uma necessidade para a ação, o autor enfatiza dois tipos de conhecimento como necessidades: enquanto modo de iluminação e progresso (aluno 7).

A utilização do verbo "enfatizar" na terceira pessoa do singular, no presente do indicativo, denota uma interpretação que o aluno desenvolve para evidenciar a relevância do ponto colocado no texto-base.

Outro exemplo vem ratificar essa visão, quando o aluno 18 utiliza o verbo na $3^{\mathrm{a}}$. Pessoa do singular "atenta":

No entanto, Cipriano nos atenta para o fato de que o conhecimento é social, não podendo assim ser adquirido de maneira individual, já que a realidade é um fator comum que une esforços em busca de seu conhecimento.

Podemos observar que os alunos, ao resumirem o texto, evidenciam sua subjetividade em relação ao texto-base, tecendo juízos de valor, o que, de certa forma, distancia das características básicas do resumo. (In)conscientemente, utilizam-se de recursos linguísticos que marcam operações discursivas que os distanciam da característica básica do resumo, ou seja, a concisão e a obediência à ideia do autor do texto-base, sem caráter avaliativo. 


\section{Considerações finais}

O objetivo principal deste artigo foi compreender o uso do resumo como estratégia de estudo, percebendo nos textos dos alunos do primeiro semestre do curso de curso de Tecnologia em Gestão Empresarial, numa universidade pública no Estado de São Paulo, aspectos recorrentes na elaboração desse gênero textual, sobretudo questões relacionadas à leitura, à produção textual e à presença da voz do texto-base no resumo.

Como já apontamos anteriormente, os alunos apresentam dificuldades ao produzir textos acadêmicos - neste caso, o resumo, por não ter domínio de algumas operações linguísticas. Uma das dificuldades encontradas na articulação desse gênero está relacionada às operações linguístico-discursivas, mais especificamente ao gerenciamento de vozes. Primeiramente, pelo fato do aluno não saber separar as ideias essenciais das secundárias do texto; depois, por não ter domínio na utilização de expressões que remetam à ideia do textobase sem explicitar um juízo de valor explicitamente, como requer o gênero textual resumo.

A leitura e a escrita são processos essenciais para a construção, aquisição e produção de conhecimento, independentemente da esfera do conhecimento humano, seja no espaço interno da escola, seja fora dela. Esses dois processos precisam ser entendidos como práticas sociais situadas, que se manifestam em diferentes gêneros.

Esta atividade demonstrou que os alunos não dominam as estratégias do "saberfazer" dessa prática discursiva inserida no domínio científico. É necessário que sejam repensadas estratégias que levem os alunos a desenvolverem a habilidade de escrita deste gênero, para que percebam os mecanismos linguísticos necessários para o funcionamento discursivo do gênero resumo acadêmico.

Podemos afirmar que, em relação à utilização de mecanismos referentes às operações linguísticas, que identificam a voz do outro no texto, os alunos interpretam possíveis operações do autor referentes ao conteúdo, ao modo de abordá-los e organizá-los, deixando, muitas vezes, de lado a principal característica do resumo, ou seja, apresentar a ideia central do texto-base, de acordo com a sequência dada por seu autor.

Esta análise leva-nos a refletir sobre a atividade de resumir textos na comunidade acadêmica. É necessário levar em consideração o fato de que as estratégias de estudo utilizadas pelos acadêmicos ao resumirem o texto servem de alicerce para a aquisição e compreensão da necessidade de ler e produzir textos que atendam às expectativas dos interlocutores.

Espera-se que esta pesquisa traga alguma contribuição para que os profissionais em Educação, em especial os dos cursos superiores, trabalhem com a produção de gêneros textuais - e, em especial, com o resumo, não apenas como uma especificidade, mas numa perspectiva dialógica e compromissada com a inserção dos sujeitos (alunos) em novos universos de conhecimentos, nas diferentes disciplinas e áreas de estudos e pesquisas.

\section{Referências}

ABNT, Norma NBR 6028. Rio de Janeiro, 2003.

BAKHTIN, M. Marxismo e Filosofia da Linguagem. Trad. Yara Frateschi. São Paulo: Hucitec, 1992.

DELL'ISOLA, R. L. P. Retextualização de gêneros escritos. Rio de Janeiro: Lucerna, 2007. 
DOLZ, J. e SCHNEUWLY, B. Gênero orais e escritos na escola. Trad. e Org. Roxane Rojo e Glaís Sales Cordeiro. Campinas: Mercado de Letras, 2004.

Os gêneros escolares: das práticas de linguagem aos objetos de ensino. In: Revista Brasileira de Educação, n. 11, 1999, p. 5-16.

FIORIN, J. L. Interdiscursividade e intertextualidade. In: BRAIT, B. Bakhtin: outros conceitos-chave. São Paulo: Contexto, 2012, p. 161-193.

GERALDI, J. W. A aula como acontecimento. São Carlos: Pedro e João Editores, 2010.

KLEIMAN, A. Texto e leitor: aspectos cognitivos da leitura. Campinas: Pontes, 1992.

KOCH, I. G. V. Desvendando os segredos do texto. São Paulo: Cortez, 2002.

LUCKESI, C. et al. Fazer Universidade: uma proposta metodológica. 14. ed. São Paulo: Cortez, 2003.

MACHADO, A. R. Revisitando o conceito de resumos. In: DIONISIO, A. P., MACHADO, A. R e BEZERRA, M. A. Gêneros textuais \& Ensino. 3. ed. Rio de Janeiro: Lucerna, 2005, p. $138-1150$.

MAINGUENEAU, D. Novas tendências em análise do discurso. 3. ed. Campinas: Ed. da UNICAMP, 1997.

MARCUSCHI, L. A. Da fala para a escrita: atividades de retextualização. São Paulo: Cortez, 2001.

. Gêneros textuais: definição e funcionalidade. In: DIONISIO, A. P., MACHADO, A. R e BEZERRA, M. A. Gêneros textuais \& Ensino. 3. ed. Rio de Janeiro: Lucerna, 2005, p.1936.

MARQUES, M. O. Escrever é preciso: o princípio da pesquisa. Ijuí: Unijuí, 1997.

MATÊNCIO, M. L. M. Atividades de (re)textualização em práticas acadêmicas: um estudo do resumo, 2003.

MILLER, C. Gênero textual, agência e tecnologia. São Paulo: Parábola, 2012

VAL, M. G. C. Redação e Textualidade. São Paulo: Martins Fontes, 1999.

VAN DIJK, T. A. Cognição, Discurso e Interação. São Paulo: Contexto, 2008.

Recebido em: julho de 2013.

Aprovado em: outubro de 2013. 